\title{
Analisis dan Desain Aplikasi Pengajuan Proposal Himpunan Mahasiswa Berbasis Web di Universitas Dinamika
}

\author{
Didiet Anindita Arnandy ${ }^{1}$, Achmad Arrosyidi ${ }^{2}$, Edo Yonatan Koentjoro ${ }^{3}$ \\ Program Studi Sistem Informasi, Universitas Dinamika \\ Email: 1didiet@dinamika.ac.id, ${ }^{2}$ achmad@dinamika.ac.id, ${ }^{3}$ edo@dinamika.ac.id
}

\begin{abstract}
Abstrak: Kegiatan Himpunan Mahasiswa (Hima) adalah salah satu kegiatan yang wajib dilakukan pada Perguruan Tinggi, sebagai bentuk aktifitas dan tanggung jawab mahasiswa yang harus di laporkan ke Kemenristekdikti melalui Borang kepada BAN-PT. Banyaknya tahapan yang harus dilalui untuk mendapatkan persetujuan proposal sampai dana bisa diterima oleh mahasiswa. Proses persetujuan yang masih dilakukan secara manual oleh mahasiswa yaitu harus datang ke bagian terkait satu persatu membuat waktu yang diperlukan menjadi lebih lama dan tidak efisien. Faktor lainnya adalah adanya format pelaporan yang tidak konsisten sehingga seringkali proposal harus mengalami revisi, persetujan dan cetak berulang kali. Padahal kegiatan harus segera dilaksanakan. Untuk itu diperlukan sebuah analisis dan desain aplikasi berbasis web untuk mengatasi masalah tersebut. Dari hasil analisa desain yang telah dibuat, diharapkan dapat membantu dalam proses implementasi pembuatan aplikasi pengajuan proposal.
\end{abstract}

Kata Kunci: Manajemen Pengajuan Proposal, Tahapan Proposal, Persetujuan Proposal

\begin{abstract}
Himpunan Mahasiswa Activity (aka HIMA) is one of the activities that must be carried out in Higher Education, as a form of student activity and responsibility that must be reported to Kemenristekdikti through Borang to BAN-PT. The number of stages that must be passed to get an approval proposal until the funds can be received by students. The approval process that is still done manually by students is to come to the relevant section one by one making the time required to be longer and inefficient. Another factor is that there are inconsistent reporting formats, so that proposals often have to be revised, agreed and printed repeatedly. Though activities must be carried out immediately. This requires an analysis and design of web-based applications to overcome these problems. From the results of the analysis of the design that has been made, it is expected to be able to assist in the implementation process of making an application for submitting a proposal.
\end{abstract}

Keywords: Management of Proposal Submission, Proposal Stages, Proposal Approval

\section{PENDAHULUAN}

Kegiatan Hima adalah salah satu kegiatan yang wajib dilakukan pada perguruan tinggi, sebagai bentuk aktifitas dan tanggung jawab mahasiswa yang harus di laporkan ke menristekdikti melalui Borang [1] kepada BANPT. Hal ini sesuai dengan Borang untuk standar 6 yaitu tentang prosedur proposal dan laporan kegiatan kemahasiswaan.

Proses pengajuan proposal dan laporan kegiatan kemahasiswaan di Universitas Dinamika dimulai dari pengajuan proposal oleh Pengurus Hima kepada Pembina Hima. Pembina Hima akan melakukan review terhadap proposal yang diberikan, jika ternyata dianggap sesuai dengan standar yang telah ditentukan maka akan diteruskan ke Kepala Program Studi untuk persetujuan. Setelah Kepala Program Studi menyetujui proposal tersebut maka diteruskan untuk mendapatkan paraf dari Wakil Dekan. Proposal yang telah mendapatkan paraf dari Wakil Dekan akan diteruskan ke Dekan untuk mendapatkan validasi dan persetujuan. Tahapan akhir pengajuan proposal adalah mendapatkan persetujuan dari Wakil Rektor I, untuk selanjutnya bagian keuangan akan melakukan 
proses untuk persiapan dana bagi proposal kegiatan mahasiswa agar dapat segera terealisasi.

Permasalahan yang dihadapi saat ini adalah banyaknya tahapan yang harus dilalui untuk mendapatkan persetujuan proposal sampai dana bisa diterima oleh mahasiswa. Proses persetujuan yang masih dilakukan secara manual oleh mahasiswa yaitu harus datang ke bagian terkait satu persatu membuat waktu yang diperlukan menjadi lebih lama dan tidak efisien. Faktor lainnya adalah adanya format pelaporan yang tidak konsisten sehingga seringkali proposal harus mengalami revisi, persetujan dan cetak berulang kali. Padahal kegiatan harus segera dilaksanakan.

Hasil penelitian terdahulu yang dilakukan oleh Taufiq Abidin dan Slamet Wiyono [2] yang telah menerapkan sistem Kemahasiswaan dan berhasil memudahkan program studi DIV Teknik Informatika dalam menyampaikan informasi tentang kemahasiswaan kepada khalayak ramai.

Penelitian Andreta Talita Pangkerego dan

Stenly Richard Pungus [3] mampu mempermudah pihak tim teknis dalam membuat dan mengakses laporan, serta pihak PPK dalam mengakses laporan dari tim teknis yang dapat dilakukan dari kantor atau dari mana saja selama PPK dapat terkoneksi dengan internet, sehingga dengan cara ini dapat mendukung kegiatan operasional.

Penelitian Bangun Teja Sulaksana [4] menyatakan bahwa sistem informasi yang telah dibuat dapat mengelola data personal anggota yang sebelumnya masih bersifat manual menjadi terkomputerisasi dan tersimpan rapi dalam sebuah database.

Penelitian Puji Santoso dan Dr. Hidarto [5] menyatakan bahwa sistem informasi yang telah dibuat dapat mempermudah organisasi untuk mengetahui infomasi status verifikasi maupun disposisi proposal dan LPJ kegiatan.

Metode pengembangan perangkat lunak yang telah diterapkan oleh Riski Wahyuniardi, Leni Herliani Afrianti, Sidik Nurjaman dan Wanda Gusdya [6] yaitu dengan menggunakan Rational Unified Process (RUP) Metode RUP merupakan metode pengembangan kegiatan yang berorientasi pada proses seperti yang terlihat pada Gambar 1. Dalam metode ini, terdapat empat tahap pengembangan perangkat lunak yaitu: 1). Inception, pengembang mendefinisikan batasan kegiatan, melakukan analisis kebutuhan user, melakukan perancangan awal perangkat lunak (perancangan arsitektural dan use case), dan merilis prototipe perangkat lunak versi Alpha, 2). Elaboration, dengan melakukan perancangan perangkat lunak mulai dari menspesifikasikan fitur perangkat lunak hingga perilisan prototipe versi Betha dari perangkat lunak, 3). Construction, yaitu implementasi rancangan perangkat lunak yang telah dibuat, sehingga perangkat lunak versi akhir yang sudah disetujui administrator dirilis beserta dokumentasi perangkat lunak, dan 4). Transition, yaitu instalasi, deployment dan sosialisasi perangkat lunak.

Untuk itu diperlukan sebuah analisis dan desain sistem untuk bisa melakukan manajemen dan monitoring pada proses pengajuan dan persetujuan proposal serta laporan yang lebih efektif dan efisien.

\section{METODE \\ Tahap Persiapan}

Tahap persiapan merupakan langkah awal sebelum melakukan penelitian yang mencakup analisis kebutuhan. Berdasarkan permasalahan yang diperoleh, maka dilakukan analisis berdasarkan data proposal yang sudah ada. Sebagai contoh, proposal yang digunakan dalam menganalisa format proposal adalah proposal POINTER yang dilaksanakan oleh Hima DIII Sistem Informasi. Ini merupakan salah satu bentuk program kerja PS DIII Sistem Informasi.

\section{Tahap Pengambilan Data}

Dalam tahap pengambilan data dilakukan dengan mengambil data proposal kegiatan POINTER 2019 yang akan dilaksanakan pada bulan November 2019. Adapun data-data proposal inti yang dibutuhkan di dalam pembuatan proposal, meliputi:

1. Nama Organisasi

2. Logo organisasi

3. Nama Kegiatan

4. Tema

5. Tanggal dan Waktu Pelaksanaan

6. Tempat

Sedangkan isi proposal yang dibutuhkan adalah sebagai berikut:

1. Latar Belakang

2. Tujuan

3. Susunan Acara

4. Anggaran Dana

5. Susunan Panitia

6. Deskripsi Pekerjaan Panitia (Job desk) 
Didit Anindita A, dkk /Journal of Technology and Informatics (JoTI) Vol.2, No.1, April 2020, 100107

7. Sumber Dana (apakah dana dari internal atau eksternal)

\section{HASIL DAN PEMBAHASAN}

\section{Analisa Permasalahan (UML Use Case)}

Dari permasalahan di atas, maka dibuatlah model perencanaan aplikasi terlebih dahulu guna membantu dalam menganalisa permasalahan. Gambar 1 menampilkan Use Case dari permasalahan yang ada.

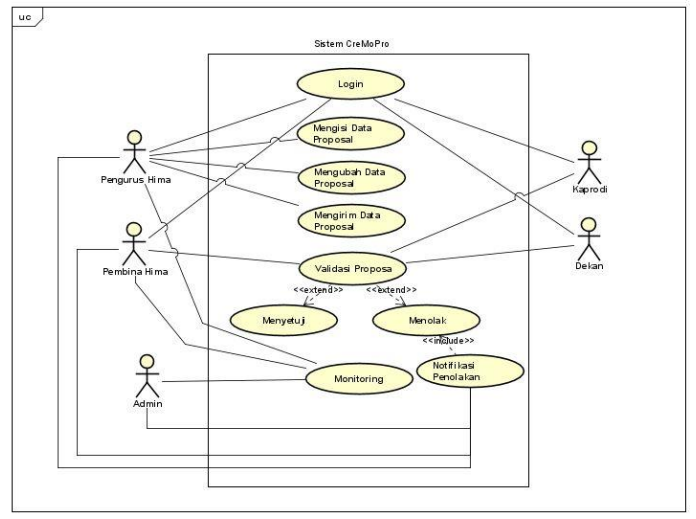

Gambar 1. Use Case Aplikasi Pengajuan

Proposal Himpunan Mahasiswa

Dari Gambar 1, terdapat 5 user yang akan berperan dalam aplikasi pengajuan proposal, yakni Mahasiswa atau pengurus Himpunan Mahasiswa (HIMA), Pembina HIMA, Ketua Program Studi (Kaprodi), Dekan, dan Admin. Proses pengajuan proposal dilakukan oleh Pengurus Hima kepada Pembina Hima. Pembina Hima akan melakukan review terhadap proposal yang diberikan. Ketika diperiksa dan sesuai dengan standar yang telah ditentukan, maka akan diteruskan kepada Kaprodi untuk persetujuan. Setelah Kaprodi menyetujui proposal tersebut, maka diteruskan untuk mendapatkan validasi dan persetujuan dari Dekan, yang kemudian diterima oleh bagian admin Fakultas untuk dicetak dan diajukan anggaran kegiatan tersebut agar dapat segera terealisasi.

\section{Pemberian Nama Aplikasi}

Setelah analisa dan perancangan telah dibuat, maka dilakukan penentuan pemberian nama program aplikasi pengajuan proposal. Aplikasi ini diberi nama dengan CreMo Pro 1.0 (Create \& Monitoring Proposal). Pemberian nama aplikasi diyakini dapat membantu user dalam mengingat keberadaan aplikasi pengajuan proposal.

\section{Pembuatan User Aplikasi}

Pada tahapan ini, dibuatlah 5 user yang memiliki hak akses, yang nantinya akan diterapkan di dalam aplikasi ini. Hal ini dapat dilihat pada Tabel 1.

Tabel 1. Tabel Hak Akses User Mahasiswa

\begin{tabular}{|c|l|}
\hline USER & \multicolumn{1}{|c|}{ HAK AKSES } \\
\hline Mahasiswa & - Melihat data akun \\
& - Merubah password. \\
& - Membuat proposal. \\
& - Monitoring proposal yang telah \\
& diajukan \\
& Mendapatkan notifikasi via e-mail. \\
\hline
\end{tabular}

Tabel 2. Tabel Hak Akses User Pembina, Ketua PS, dan Dekan Fakultas

\begin{tabular}{|c|c|}
\hline USER & HAK AKSES \\
\hline $\begin{array}{l}\text { Pembina } \\
\text { Himpunan } \\
\text { Mahasiswa }\end{array}$ & $\begin{array}{l}\text { - Melihat data akun. } \\
\text { - Merubah password. } \\
\text { - Memeriksa proposal yang masuk dari } \\
\text { mahasiswa. } \\
\text { - Memberikan saran/kritik melalui kolom } \\
\text { komentar yang telah disediakan. } \\
\text { - Menentukan apakah proposal diterima/ } \\
\text { direvisi. } \\
\text { - Monitoring proposal yang telah } \\
\text { diajukan oleh mahasiswa. } \\
\text { Mendapatkan notifikasi via } e \text {-mail. }\end{array}$ \\
\hline Ketua PS & $\begin{array}{l}\text { - Melihat data akun. } \\
\text { - Merubah password. } \\
\text { - Memeriksa proposal yang masuk dari } \\
\text { mahasiswa dan telah disetujui oleh } \\
\text { Pembina Hima. } \\
\text { - Memberikan saran/kritik melalui kolom } \\
\text { komentar yang telah disediakan. } \\
\text { - Menentukan apakah proposal diterima/ } \\
\text { direvisi. } \\
\text { - Monitoring proposal yang telah } \\
\text { diajukan oleh mahasiswa. } \\
\text { Mendapatkan notifikasi via e-mail. }\end{array}$ \\
\hline $\begin{array}{l}\text { Dekan } \\
\text { Fakultas }\end{array}$ & $\begin{array}{l}\text { - Melihat data akun. } \\
\text { - Merubah password } \\
\text { - Memeriksa proposal yang masuk dari } \\
\text { mahasiswa dan telah disetujui oleh } \\
\text { Ketua PS. } \\
\text { - Memberikan saran/kritik melalui kolom } \\
\text { komentar yang telah disediakan. } \\
\text { - Menentukan apakah proposal diterima/ } \\
\text { direvisi. } \\
\text { - Monitoring proposal yang telah } \\
\text { diajukan oleh mahasiswa. } \\
\text { Mendapatkan notifikasi via e-mail.. }\end{array}$ \\
\hline
\end{tabular}

Tabel 2. Tabel Hak Akses User Admin Fakultas 
Didit Anindita A, dkk /Journal of Technology and Informatics (JoTI) Vol.2, No.1, April 2020, 100107

\begin{tabular}{|l|l|}
\hline \multicolumn{1}{|c|}{ USER } & \multicolumn{1}{|c|}{ HAK AKSES } \\
\hline Admin & - Melihat data akun. \\
Fakultas & - Merubah password. \\
& - Memeriksa proposal yang masuk dari \\
& mahasiswa dan telah disetujui oleh \\
& Pembina, Ketua PS, dan Dekan \\
& Fakultas. \\
& - Mencetak proposal yang nantinya akan \\
& diajukan kepada Wakil Rektor I dan \\
& bagian Keuangan. \\
& Memberikan informasi berupa \\
& saran/kritik melalui kolom komentar \\
& yang telah disediakan. \\
& Menentukan apakah proposal diterima/ \\
& direvisi. \\
& Monitoring proposal yang telah \\
& diajukan oleh mahasiswa. \\
& Mendapatkan notifikasi berupa e-mail \\
& untuk proposal yang masuk dan diminta \\
untuk diajukan kepada Wakil Rektor I dan & bagian keuangan. \\
\hline
\end{tabular}

\section{Physical Data Model}

Setelah perancangan desain aplikasi pengajuan proposal, maka disusunlah rancangan database yang akan digunakan di dalam aplikasi. Gambar 2 menampilkan bentuk Physical Data Model (PDM).

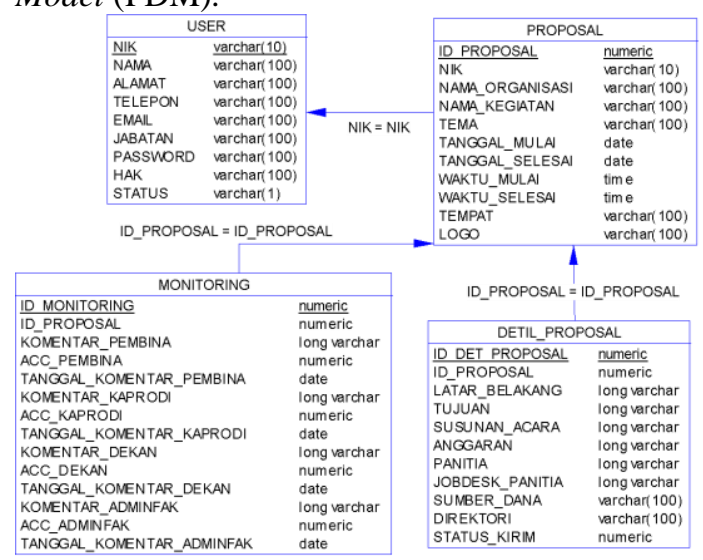

Gambar 2. Physical Data Model pada Aplikasi

Pengajuan Proposal Himpunan Mahasiswa

Berdasarkan Gambar 2. Terdapat empat tabel, yaitu tabel USER, PROPOSAL, DETIL_ PROPOSAL, dan tabel MONITORING. Tabel USER digunakan untuk menyimpan semua informasi terkait user yang menggunakan aplikasi tersebut. Informasi ini nantinya akan digunakan dalam lembar laporan persetujuan proposal. Tabel PROPOSAL dan DETIL_PROPOSAL berisi semua informasi yang digunakan di dalam pembuatan proposal kegiatan. Tabel MONITORING berisi komentar dan status diterima/direvisi dari masing-masing pimpinan.

\section{Desain Sistem}

Pada tahapan ini, dibuatlah desain user interface dalam bentuk sebuah mockup. Hal ini bertujuan untuk membantu memvisualiasikan bentuk program yang nantinya akan dibangun.

Langkah pertama yang dilakukan oleh penulis dalam mebuat mockup adalah menentuk nama program aplikasi pengajuan proposal. Aplikasi ini diberi nama dengan CreMo Pro 1.0 (Create \& Monitoring Proposal). Pemberian nama aplikasi diyakini dapat membantu user dalam mengingat keberadaan aplikasi pengajuan proposal.

Langkah selanjutnya, adalah membuat mockup untuk masing-masing user. Pembuatan mockup ini hanya menggunakan 2 (dua) user saja, yakni user mahasiswa dan user Pembina Hima. Hal ini dikarenakan tampilan mockup pembina sama dengan tampilan mockup Ketua PS, Dekan Fakultas, dan Admin Fakultas. Perbedaannya adalah fungsionalitas dan tampilan yang disajikan. Hal ini akan terlihat ketika sudah dibangun aplikasi CreMo Pro 1.0. Gambar 3 menampilkan laman login dari aplikasi CreMo Pro 1.0

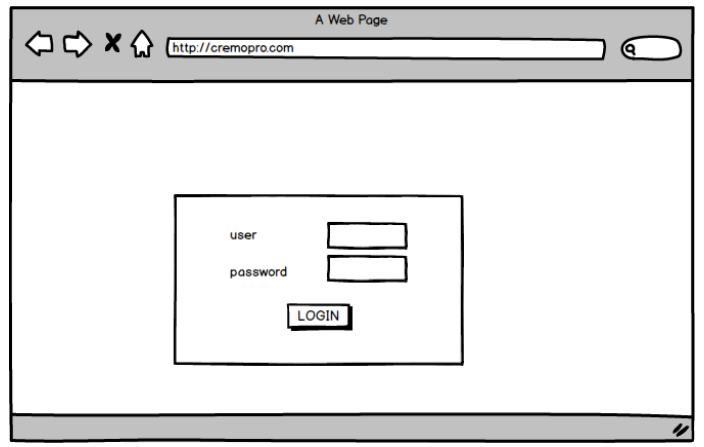

Gambar 3. Laman Login CreMo Pro 1.0

Input login yang digunakan untuk mengakses aplikasi ini adalah user dan password. Setiap user, akan diberikan id user dan password. Password nantinya dapat diubah sesuai dengan kebutuhan user.

Pada laman mahasiswa, terdapat 2 (dua) sisi yang ditampilkan dalam laman dashboard CreMo Pro 1.0. Sisi di sebelah kiri menggambarkan tentang sidebar atau pilihan fitur yang disediakan. Sedangkan di sisi sebalah kanan menampilkan informasi yang ditampilkan pada setiap fitur yang dipilih. Terdapat 4 (empat) fitur utama yang ditampilkan pada aplikasi CreMo Pro 1.0, yaitu Dashboard, Akun, Proposal, dan Monitoring. Menu "Akun" dan menu "Proposal" memiliki 
Didit Anindita A, dkk /Journal of Technology and Informatics (JoTI) Vol.2, No.1, April 2020, 100107

beberapa menu tambahan. Gambar 4. Menampilkan isi menu "Akun" dan menu "Proposal".

\begin{tabular}{|l|}
\hline Dashboard \\
\hline Akun \\
\hline Data Akun \\
Ubah Password \\
\hline Proposal \\
\hline Monitoring \\
\hline
\end{tabular}

\begin{tabular}{|l|}
\hline Dashboard \\
\hline Akun \\
\hline Proposal \\
\hline Buat Proposal \\
Data Proposal \\
\hline Monitoring \\
\hline
\end{tabular}

Gambar 4. Menu Akun dan Menu Proposal CreMo Pro 1.0 Pada User Mahasiswa

Menu "Akun" berisi "Data Akun" dan "Ubah Password". Sedangkan pada menu "Proposal" berisi "Buat Proposal" dan "Data Proposal". Masing-masing fitur menu akan dijelaskan satu per satu pada bagian berikutnya.

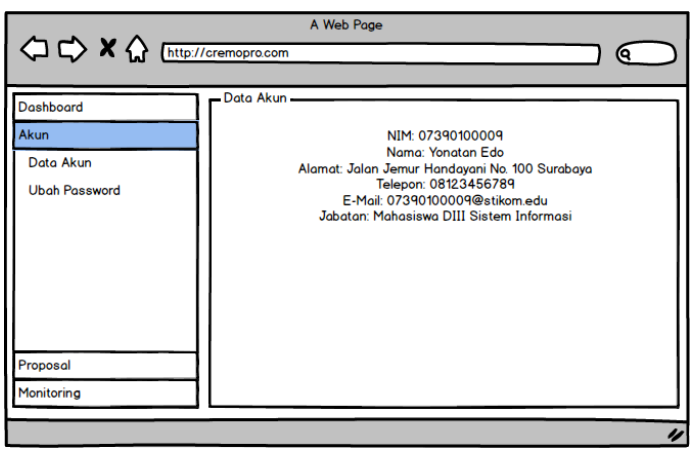

Gambar 5. Laman "Data Akun" CreMo Pro 1.0 Pada User Mahasiswa

Gambar 5 menampilkan laman data akun. Data akun berisi semua informasi dari akun user mahasiswa bernama "Yonatan Edo". Adapun informasi yang ada berupa NIM, Nama, Alamat, Telepon E-mail, dan Jabatan.

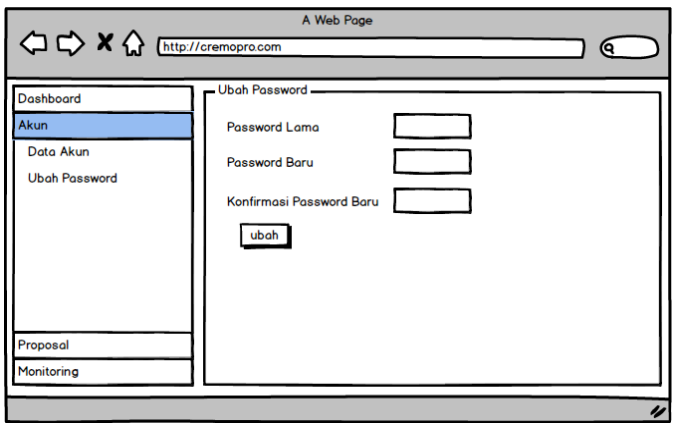

Gambar 6. Laman "Ubah Password" CreMo Pro 1.0 Pada User Mahasiswa
Sedangkan menu "Ubah Password" pada Gambar 6 menampilkan laman ubah password yang dapat digunakan user untuk mengganti user dan passwordnya.

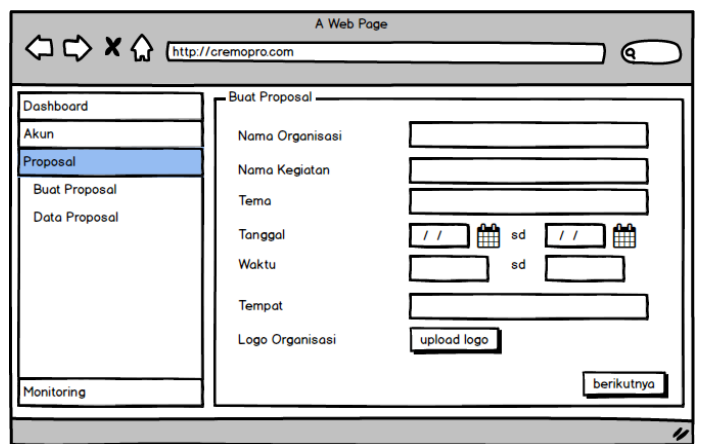

Gambar 7. Laman "Buat Proposal-Tahap 1" CreMo Pro 1.0 Pada User Mahasiswa

Gambar 7 menampilkan tahapan pertama dalam pembuatan proposal. Dalam laman ini, user memasukan data berupa nama organisasi, nama kegiatan, tema, tanggal dan waktu pelaksanaan, tempat, dan logo organisasi. Setelah semua informasi telah dimasukan, maka user akan menekan tombol berikutnya untuk menuju ke tahap kedua dalam pembuatan proposal.

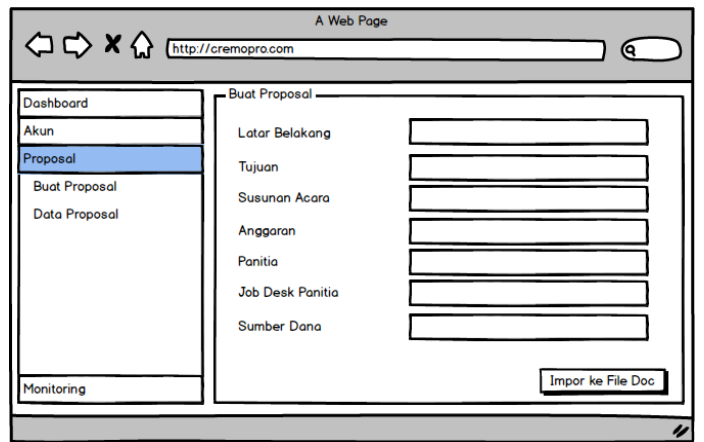

Gambar 8. Laman "Buat Proposal-Tahap 2" CreMo Pro 1.0 Pada User Mahasiswa

Gambar 8 menampilkan tahapan kedua dalam pembuatan proposal. Dalam laman ini, user memasukan latar belakang, tujuan, susunan acara, anggaran, susunan panitia, job desk panitia, dan sumber dana. Dalam laman ini, ada sedikit perbedaan dalam mengisi kotak yang disediakan. User dapat memberikan beberapa edit-an format untuk membantu dalam penyusunanan proposal. Pengunaan tabel dan gambar juga disediakan di dalam laman ini untuk menjelaskan informasi 
Didit Anindita A, dkk /Journal of Technology and Informatics (JoTI) Vol.2, No.1, April 2020, 100107

kegiatan yang akan dilakukan. Gambar 9 menampilkan bentuk text editor yang digunakan.

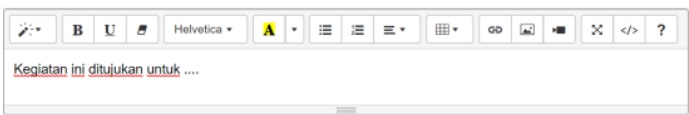

\section{Gambar 9. Text Editor}

Jika semua informasi dalam penyusunan poposal, maka user dapat melakukan "import ke file Doc". Segala informasi yang telah diisi akan dimasukan ke dalam database dan akan dibuatkan sebuah file Doc yang nantinya akan dapat diunduh sebagai arsip. Gambar 10 menampilkan tahap terakhir dalam pembuatan proposal.

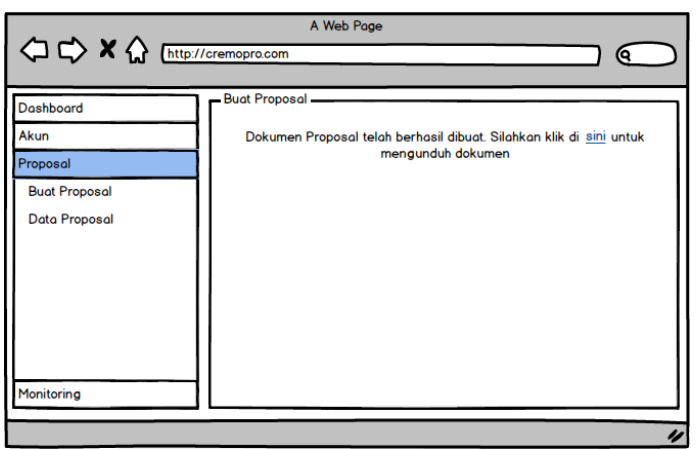

Gambar 10 Laman "Buat Proposal-Tahap 3" CreMo Pro 1.0 Pada User Mahasiswa

Perlu diketahui bahwa pembuatan proposal ini hanya bersifat satu arah saja. Artinya informasi proposal ini belum sepenuhnya selesai tanpa adanya persetujuan dari beberapa pihak terkait, seperti Pembina Hima, Ketua PS, Dekan, dan Admin Fakultas. Untuk itu, di dalam aplikasi ini, user harus menekan tombol "kirim" pada menu "data proposal". Informasi ini akan dijelaskan pada tahap selanjutnya.

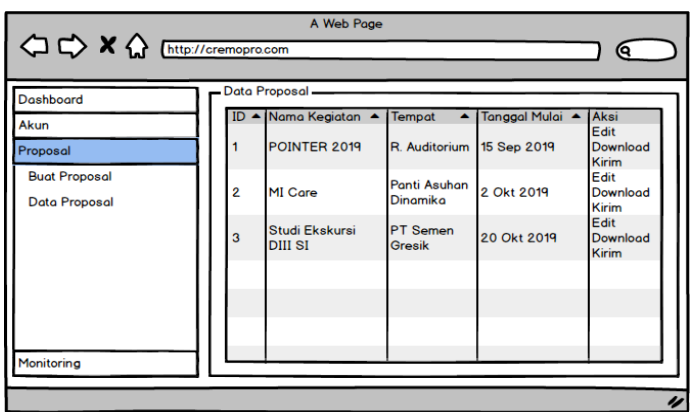

Gambar 11. Laman "Data Proposal" CreMo Pro 1.0 Pada User Mahasiswa

Gambar 11 menampilkan laman data proposal yang telah dibuat oleh user. Pada setiap proposal yang telah dibuat, terdapat 3 (tiga) aksi yang dapat dilakukan, yakni "Edit", "Download", dan "Kirim". Pada menu "Edit", berisi data proposal yang nantinya dapat diperbarui lagi oleh user. Hal ini dimungkinkan agar tidak terjadi banyaknya pengiriman dokumen proposal kepada Pembina Hima. Gambar 12, Gambar 13, dan Gambar 14 menampilkan laman edit proposal.

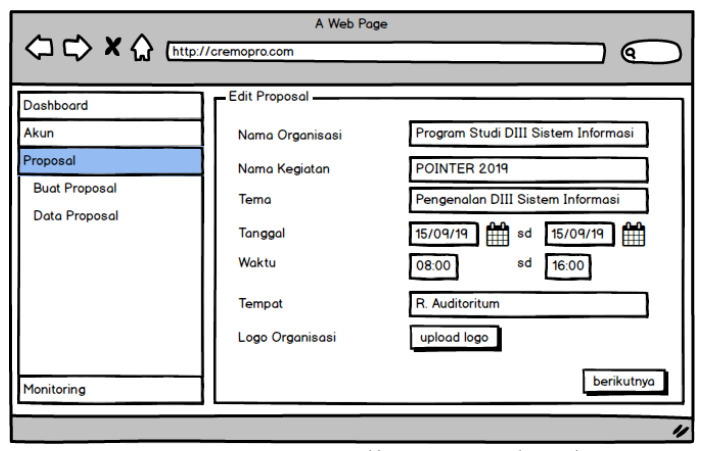

Gambar 12. Laman "Edit Proposal-Tahap 1" CreMo Pro 1.0 Pada User Mahasiswa

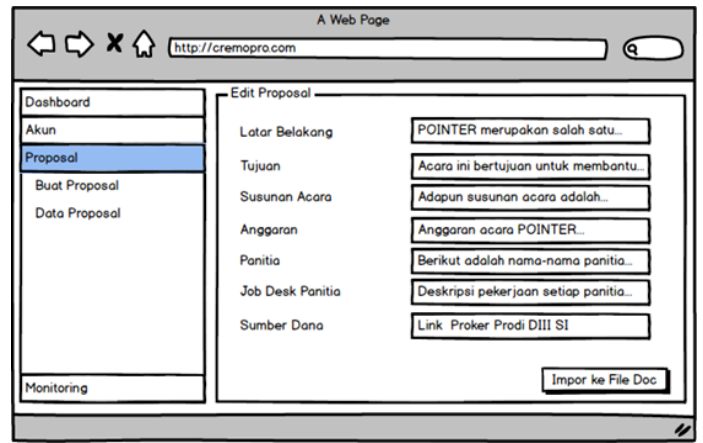

Gambar 13. Laman "Edit Proposal-Tahap 2" CreMo Pro 1.0 Pada User Mahasiswa

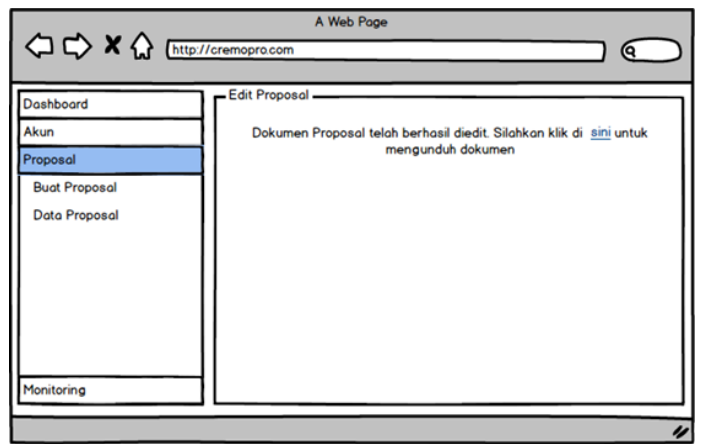

Gambar 14. Laman "Edit Proposal-Tahap 3" CreMo Pro 1.0 Pada User Mahasiswa

Tampilan laman "Edit Proposal" sama dengan tampilan laman "Buat Proposal". Yang membedakan dari kedua dari hal ini adalah 
Didit Anindita A, dkk /Journal of Technology and Informatics (JoTI) Vol.2, No.1, April 2020, 100107

informasi yang terdapat pada laman "Edit Proposal". Hal ini akan memudahkan user jika membutuhkan perubahan data yang harus di-edit. Sehingga user cukup melihat dari satu halaman saja.

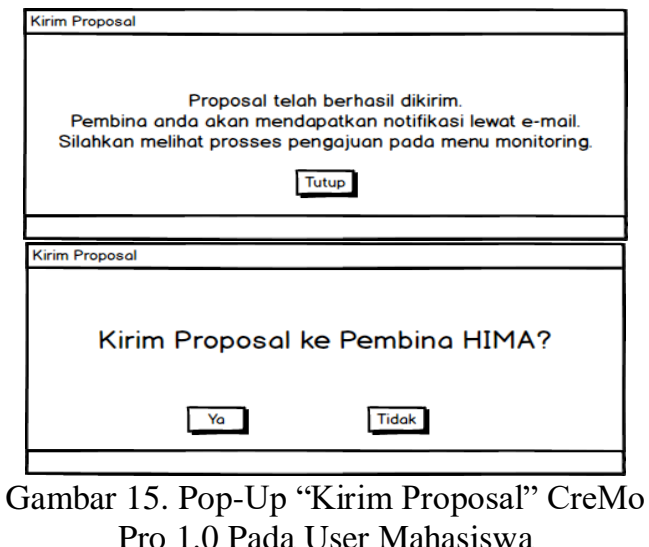

Gambar 15 menampilkan pop-up jika user menekan tombol "Kirim". Tombol ini berfungsi untuk mengirimkan notifikasi berupa e-mail ke Pembina Hima agar dilakukan pemeriksaan proposal.

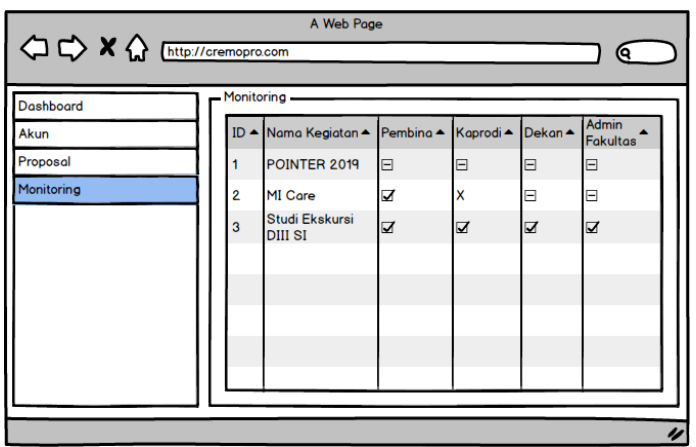

Gambar 16. Laman "Monitoring" CreMo Pro 1.0 Pada User Mahasiswa

Gambar 16 menampilkan laman "Monitoring" yang dapat digunakan sebagai media pelacakan proposal yang telah diajukan. User dapat mengetahui proposal kegiatan sudah diterima dan disetujui/direvisi.

Perbedaan yang terlihat dalam user mahasiswa dengan user Pembina/Kaprodi/Dekan/ Admin dalam laman aplikasi CreMo Pro 1.0 adalah pada pemeriksaan proposal, apakah proposal tersebut mendapatkan persetujuan atau perlu dilakukan revisi. Gambar 17 menampilkan tahapan pertama dalam pemeriksaan proposal.
Dalam laman ini, user dapat melihat proposal yang belum diperiksa. Jika user akan melakukan pemeriksaan proposal, maka user dapat menekan tombol "Detil" yang telah disediakan di bagian kanan.

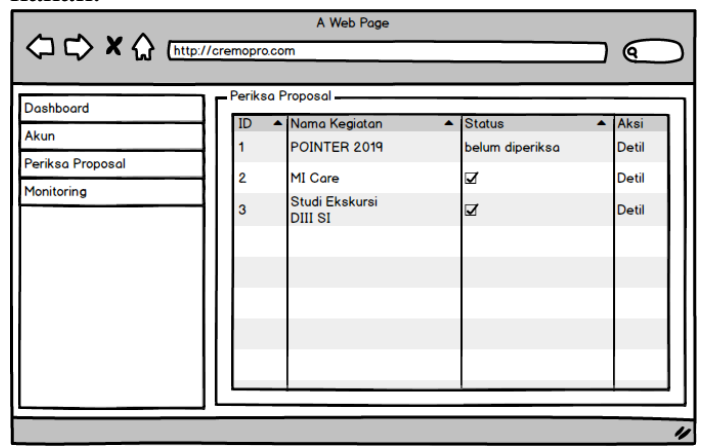

Gambar 17. Laman "Periksa Proposal-Tahap 1" CreMo Pro 1.0 Pada User

Gambar 18 menampilkan informasi detil dari proposal yang telah dipilih. Pada laman ini, user dapat mengunduh file proposal dan memeriksanya terlebih dahulu. Dari hasil pemeriksaan, user dapat memberikan status proposal tersebut diterima atau tidak, serta memberikan komentar berupa masukan yang dapat digunakan untuk merevisi proposal kegiatan.

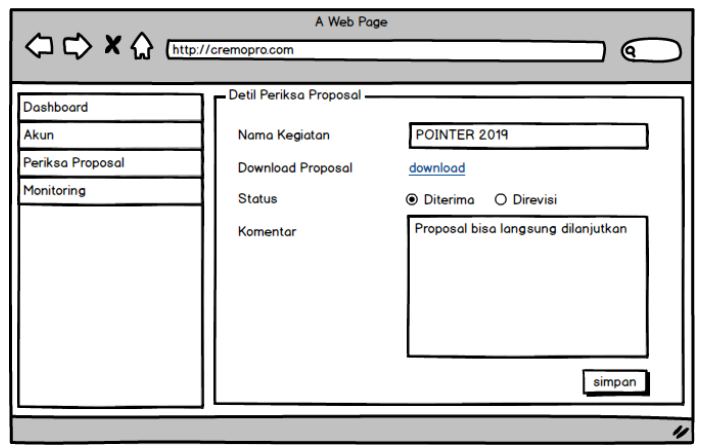

Gambar 18. Laman "Detil Periksa Proposal" CreMo Pro 1.0 Pada User

Setelah semua informasi telah dimasukan oleh user, maka user menekan tombol "simpan", dimana akan menampilkan pop-up seperti pada Gambar 19. Proses penyimpanan yang dilakukan akan memberikan notifikasi kepada penerima (mahasiswa dan pimpinan level berikutnya (apabila disetujui) agar mereka dapat mengetahui perkembangan proposal kegiatan. 
Didit Anindita A, dkk /Journal of Technology and Informatics (JoTI) Vol.2, No.1, April 2020, 100107

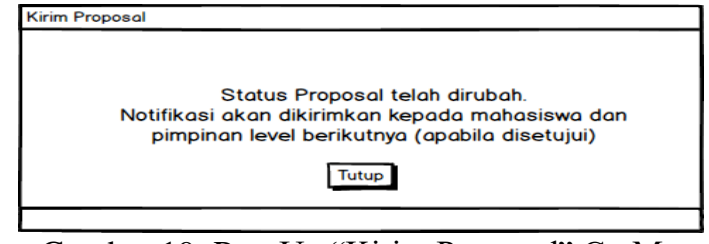

Gambar 19. Pop-Up "Kirim Proposal” CreMo

Pro 1.0 Pada User

Gambar 20 menampilkan laman "Monitoring" yang dapat digunakan sebagai media pelacakan proposal yang telah diajukan. User dapat mengetahui jika proposal kegiatan sudah diterima dan disetujui/direvisi. Tampilan laman ini sama dengan tampilan user mahasiswa.

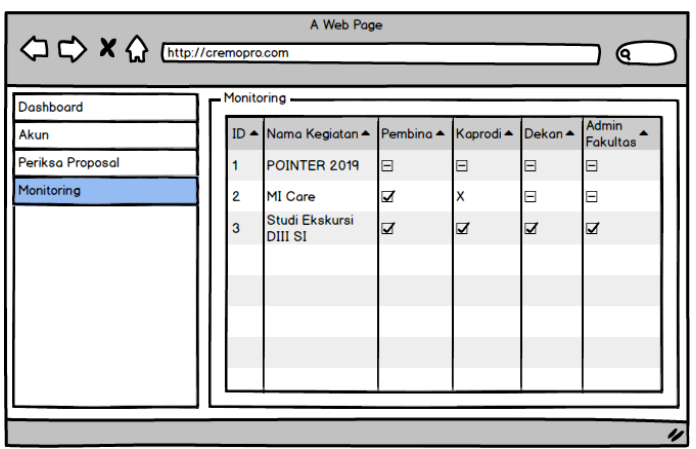

Gambar 20. Laman "Monitoring" CreMo Pro 1.0 Pada User

\section{KESIMPULAN}

Berdasarkan hasil analisis dan desain aplikasi pengajuan proposal Himpunan Mahasiswa (Hima) berbasis web di Universitas Dinamika, maka dapat disimpulkan sebagai berikut:

a. Telah dilakukan identifikasi permasalahan untuk penelitian dengan mengetahui masalah yang terjadi.

b. Hasil analisis untuk identifikasi permasalahan dengan mengetahui kebutuhan apa saja yang terdapat di dalam pembuatan proposal dan bagaimana alur sistem.

c. Pembuatan desain sistem berupa desain database dan mockup dalam pembuatan aplikasi CreMo Pro 1.0.

\section{SARAN}

Dari hasil analisa dan desain aplikasi yang telah dibuat, diharapkan dapat diimplementasikan ke dalam pembuatan program sehingga dapat membantu Himpunan Mahasiswa dalam proses pengajuan proposal kegiatan.

\section{DAFTAR PUSTAKA}

[1] Borang, 2014, Prodi DIII Sistem Informasi. Buku IIIA Borang Akreditasi DIII Manajemen Informatika, Universitas Dinamika, Surabaya

[2] T. Abidin dan S. Wiyono, "Rancang Bangun Sistem Informasi Kemahasiswaan (Studi Kasus: Program Studi D IV Teknik Informatika Politeknik Harapan Bersama Tegal)". Jurnal Informatika: Jurnal Pengembangan IT, vol. 2 no. 1, hal. 30-36, 2017

[3] A.T. Pangkerego, dan S. Richard Pungus. 2016. Perancangan Aplikasi Laporan Kegiatan Berbasis Web Pada Bpjn Xi Satker Wilayah Ii Sulawesi Utara, OJS Universitas AMIKOM Yogyakarta, vol. 4 no. 1, hal 67, 2016

[4] B.T. Sulaksana, (2014) Rancang Bangun Sistem Informasi Berbasis Web Pada Organisasi Purna Paskibraka Indonesia Gunungkidul Sebagai Media Informasi Dan Publikasi, Repository AMIKOM [Online] http://repository.amikom.ac.id/files/Publika si_07.12.2716.pdf, tanggal akses: 28 Februari 2019.

[5] P. Santoso. dan Hidarto. (2016). Rancang Bangun Sistem Informasi Proposal Kegiatan Kemahasiswaan Studi Kasus Kemahasiswan Universitas Muhammadiyah Sidoarjo. ACADEMIA [ONLINE] https://www.academia.edu/28338308/, tanggal akses: 28 Februari 2019.

[6] R. Wahyuniardi, L. H. Afrianti, S. Nurjaman, dan W. Gusdya, "Sistem Informasi Berbasis Web Untuk Monitoring Dan Evaluasi Sentra Industri Kecil Di Jawa Barat. Jurnal Ilmiah Teknik Industri Universitas Muhammadiyah Surakarta", Jurnal Ilmiah Teknik Industri, 174-186. doi:10.23917/jiti.v14i2.1049, Des. 2015 